\title{
Experimental Study on Effect of Electrode Location on Ion Current
}

\author{
Hanqing $\mathrm{Xu}^{1}$, Weijun Fan ${ }^{1}$ and Rongchun Zhang ${ }^{1, a}$ \\ ${ }^{1}$ National Key Laboratory on Aero-Engines, School of Energy and Power Engineering, Beihang University, Beijing, \\ China
}

\begin{abstract}
In an attempt to use ion current method on a suction flame holder for combustion diagnosis, the position of the detection electrode that has the significant effect on ion current, should be investigated. The objective of this study was to experimentally investigate the ion current distribution in different combustion zones by changing the electrode length and streamwise location. An ion current acquisition system was built on basis of the principle of Langmuir probe, and experiments were conducted under different fuel-air ratios ranging from $0.008 \sim 0.022$. The results suggest that the ion current distribution obeys the same regulation at different fuel-air ratios. With the electrode length increasing, the ion current increases first, then decreases, and finally presents a unimodal curve. As the electrode streamwise location increases, the ion current demonstrates a linear decrease rule. The maximum ion current is obtained in the case that the electrode length and streamwise location equals $60 \mathrm{~mm}$ and 0.75 . Since the larger ion current provides the wider range for setting the misfire threshold, the position where the maximum ion current occurs can be a better choice for arranging the electrode.
\end{abstract}

\section{Introduction}

Bluff-body flame holders are commonly used to stabilize flames in high-speed airflows, and one of their engineering applications is turbojet afterburner[1]. Suction flame holder, a variant structure of Vee gutter flame holder, has been successfully applied to a certain turbojet afterburner[2]. Corrugated slots symmetrically arranged both on the tail edge of its sidewalls result in better ignition performance, higher combustion efficiency and improved lean blowout $(L B O) \operatorname{limit}[3]$. However, compared with the main combustor, severe inlet conditions for afterburners including lower pressure, lower oxygen and higher velocity have greatly negative effect on $L B O$ limit[4]. If blowout occurs, the afterburner will lose thrust augmentation critical to the maneuverability of tactical aircrafts. Whereas if $L B O$ is well predicted, the reliability of a fighter will be enhanced.

Many researches have been conducted on predictions of the precursor events prior to incipient $L B O$ phenomenon in various combustors. These experimental studies primarily used three methods, which include the acoustic method with a condenser microphone, the optical method with a fused silica optical fiber and the electrical method with a pair of charged electrodes. Moreover, images taken

\footnotetext{
${ }^{a}$ Corresponding author: zhangrongchun@buaa.edu.cn
} 
by a high-speed ICCD camera and dynamic pressure signals collected by a high-frequency pressure transducer were adopted as auxiliary approaches to understand the transient flame dynamics better.

The first two methods are usually employed together to validate the results by each other. For instance, Muruganandam and Nair used the chemiluminescence and acoustic radiation from a premixed dump combustor to characterize the transient flame behavior approached $L B O$ as short duration, localized extinction and reignition events[5]. They also observed the variations in lowfrequency acoustic spectrum and increased presence of intermittent events in both acoustic and optical data from a swirl cup combustor[6]. Bompelly and Lieuwen detected the proximity of $L B O$ in a premixed swirl combustor using flame chemiluminescence and acoustic signatures, and extended the means for $L B O$ limit sensing[7]. Bompelly and Seitzman found that threshold of the low-pass filtered chemiluminescence signal could provide robust precursor identification of $L B O$ in a lean direct injection combustor[8]. Yi successfully predicted the proximity to $L B O$ based on chemiluminescence signals and global images[9]. Aditya and Muruganandam sensed the precursor events occurred and reoccurred in an interval of several milliseconds before $L B O$ using a photodiode sensor and a highspeed imaging camera[10].

The ion current probes, based on chemiionization and thermal ionization, have been applied to combustion diagnosis in some HCCI engines and gas turbine model combustors. As to HCCI engines, Strandh affirmed the existence of ion current sensitive to the fuel-air ratio[11]. Vressner and Andreas examined the effects of fuel type and probe location on the ion current $[12,13]$. Chen and Panousakis proved that ion current can be a cost effective and adequately informative feedback signal for engine control[14]. Dong constructed the phase relation between ion current signal and combustion phase[15]. With respect to gas turbine model combustors, Chorpening developed an ion current sensor to detect the $L B O$ and combustion instabilities[16]. Nair and Rajaram invented a novel ignition system with ion sensing capability used for $L B O$ detection[17]. Keshav certified the ion current from a supersonic combustion flow could be used as a flame indicator for feedback combustion control[18].

Optical and acoustic sensors have the advantages of non-direct contact to the high-temperature flames, while are confined to open an observation window. In order to arrange the optical access and devices on a gas turbine combustor, both the combustor casing and liner must be penetrated, which would destroy the structural integrity and strength. Ion current probes have the merits of instant response and simple structure, but are sensitive to their locations mainly due to the heterogeneous diffusion combustion after the flame holder. With a view to the reliability of an aircraft, the ion current probe has more potential for combustion diagnosis than other sensors provided that the best ion sensor location can be determined.

In this paper, an ion current acquisition system was established on basis of the principle of Langmuir probe, and experiments were conducted under different fuel-air ratios. In order to get a better location for the detection probe, ion current distributions in different combustion zones was investigated by changing the electrode length and location. The results could provide guidance for the location arrangement of the detection probes used to diagnose the misfire after a flame holder.

\section{Method}

\subsection{Measurement Principle}

As the fuel-air mixture after the flame holder is ignited, a great amount of charged ions stably emerge. The main source of ions is provided by chemiionization. The most important reaction in the process is considered as followed[19]:

$$
\mathrm{CH}+\mathrm{O} \rightarrow \mathrm{CHO}^{+}+e^{-}
$$

Owing to charge transfer reactions, $\mathrm{CHO}^{+}$is quickly consumed by $\mathrm{H}_{2} \mathrm{O}$ via: 


$$
\mathrm{CHO}^{+}+\mathrm{H}_{2} \mathrm{O} \rightarrow \mathrm{CO}+\mathrm{H}_{3} \mathrm{O}^{+}
$$

In SI engines or gas turbine combustors, the high temperature is encountered after ignition, thus thermal ionization may play an important role[20].

After loading an external electric field on the combustion field, these ions will move forth and back, and then a certain type of electric current called ion current flows through the circuit. As shown in Figure 1, a Langmuir probe system, including DC bias power supply $(E)$, sample resistance $\left(R_{1}\right)$, slide rheostat $\left(R_{2}\right)$, positive probe and flame holder, was used to detect the ion current. Table 1 lists the parameter values of the system. By collecting the voltage drop $(u)$ of the sample resistance, the ion current $(I)$ can be expressed as

$$
I=u / R_{1}
$$

During the experiments, a cylindrical metal stick as the central probe was penetrated into the flame region, and another probe was the flame holder connected with the combustor walls. Based on the results of experiments conducted on a constant volume combustion bomb, the combustor wall and central probe respectively served as the negative and positive probe[21].

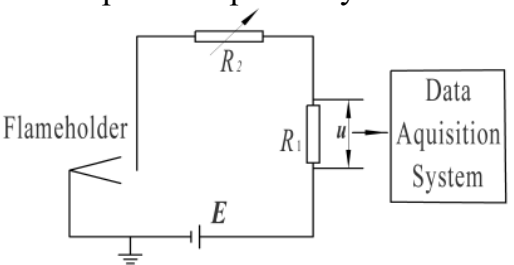

Table 1. Langmuir probe system parameters

Figure 1. Schematic of the Langmuir probe system

\begin{tabular}{|c|c|}
\hline Parameter & Value \\
\hline Bias supply $(E)[\mathrm{V}]$ & 24 \\
\hline Sample resistance $\left(R_{1}\right)[\Omega]$ & 110 \\
\hline Slide rheostat $\left(R_{2}\right)[\Omega]$ & $0-470 \mathrm{~K}$ \\
\hline Positive $\operatorname{probe}(\Phi)[\mathrm{mm}]$ & 4 \\
\hline
\end{tabular}

\subsection{Test Rig Configuration}

Test rig mainly consisted of three components: test section, flame holder and oil supply unit.

Figure 2 shows the structure of 2D test section. The spanwise width and vertical height of the outlet section were separately $160 \mathrm{~mm}$ and $120 \mathrm{~mm}$. The positive electrode was mounted vertically on a displacement mechanism.

Figure 3 shows the suction flame holder containing a main flame holder, an outer cover, a fuel injector and a splash plate. Table 2 lists the primary structure parameters of the flame holder. Subscript 0 and 1 severally denote the main flame holder and the outer cover. Three-dimensional Cartesian coordinates were employed in the flow field and the origin of that was placed the middle of the outlet cross section of the outer cover.
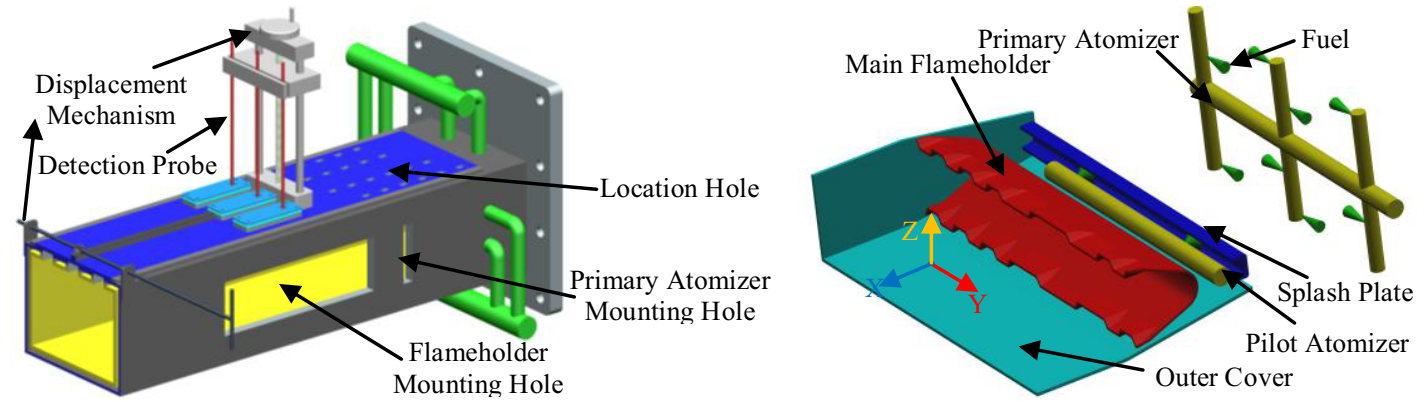

Figure 2. Schematic of the test section

Figure 3. Schematic of the flameholder

Table 2. Flame holder structural parameters

\begin{tabular}{|c|c|c|c|c|c|c|c|c|}
\hline \multirow{3}{*}{ Parameter } & \multicolumn{2}{|c|}{$\begin{array}{c}\text { Flare angle } \\
(\alpha)\left[{ }^{\circ}\right]\end{array}$} & \multicolumn{2}{|c|}{$\begin{array}{c}\text { Spanwise width } \\
(W)[\mathrm{mm}]\end{array}$} & \multicolumn{2}{c|}{$\begin{array}{c}\text { Groove width } \\
(D)[\mathrm{mm}]\end{array}$} & \multicolumn{2}{c|}{$\begin{array}{c}\text { Streamwise length } \\
(L)[\mathrm{mm}]\end{array}$} \\
\cline { 2 - 9 } & $\alpha_{0}$ & $\alpha_{1}$ & $W_{0}$ & $W_{1}$ & $D_{0}$ & $D_{1}$ & $L_{0}$ & $L_{l}$ \\
\hline Value & 45 & 30 & 156 & 156 & 34 & 40 & 32 & 102 \\
\hline
\end{tabular}


Oil supply unit included a pilot atomizer and a primary atomizer. The former was a splash-plate plain orifice injector and the latter was a normal plain orifice injector situated $110 \mathrm{~mm}$ upstream from the main flame holder lead edge. The orifice diameter was $0.5 \mathrm{~mm}$.

\subsection{Experimental System}

The schematic of experimental system expressed in Figure 4 was comprised of four subsystems.

1. Air source

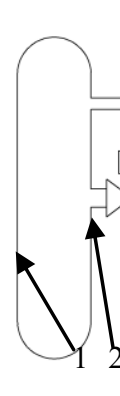

2. Electric stop valve

3. Electric adjustable valve

4. Orifice plate flowmeter

5. Preheat combustor

6. Settling chamber

7. Temperature rake

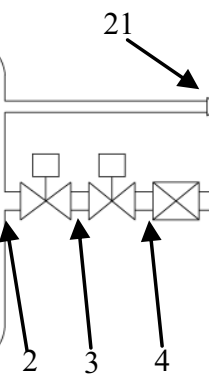

(1)

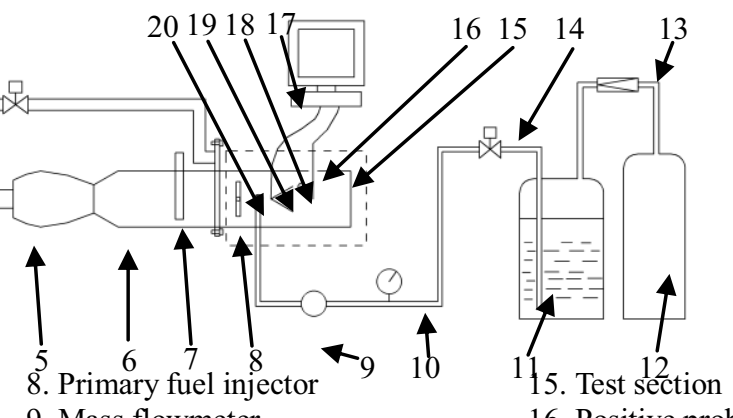

9. Mass flowmeter

10. Pressure gauge

11. Fuel tank

12. Nitrogen bottle

13. Dropping valve

14. Manual needle valve
16. Positive probe

17. IPC

18. Igniter

19. Flame holder

20. Pilot fuel injector

21. Manual stop valve

Figure 4. Schematic of the experimental system

Air Supply System. Air from main air source was divided into the mainstream air and cooling air. The flow rate of mainstream air was controlled by an electric adjustable valve and monitored by an orifice plate flowmeter. The flow rate of cooling air was regulated by a manual stop valve. The mainstream vitiated air was heated by a preheat combustor and the temperature was measured by 22 K-type thermocouples.

Fuel Supply System. It mainly composed of high-pressure nitrogen gas bottle, fuel tank, mass flowmeter and fuel injector. The fuel type was aviation kerosene and the mass flow rate was monitored by a DMF-1A Coriolis mass flowmeter.

Ion Current Transducer System. The key components of this system is depicted in Figure 1.

Data Acquisition System. The voltage induced by ion current was collected by a DH3816 static stress testing system. In consideration of the periodical vortex shedding behind the flame holder, each data point was measured continuously 5 times and the arithmetic mean was taken as the steady state value. Temperature signal was acquired by the ADVANTECH IPC.

\subsection{Experimental Conditions}

The experimental conditions, including inlet Mach number $(M a=0.2)$, inlet total temperature $\left(T_{\mathrm{in}}=623 \mathrm{~K}\right)$, electrode spanwise location $(\tilde{Y}=-1.25)$, and fuel-air ratio $(f=0.008-0.022)$, remained the same for all experiments.

The fuel-air ratio $(f)$ was defined as

$$
f=\dot{m}_{f} / \dot{m}_{a}
$$

where, $\dot{m}_{f}$ was the total mass flow rate of aviation kerosene from the pilot and primary atomizers, $\dot{m}_{a}$ was the mass flow rate of preheated main airstream. When $f=0.008$, fuel was injected only by the pilot atomizer. But when $f$ overs 0.008 , the mass flow rate of pilot atomizer remained unchanged with $f=0.008$, and then that of primary atomizer was increased to the preset values.

The electrode streamwise location $(\tilde{X})$ and spanwise location $(\tilde{Y})$ were individually defined as 


$$
\begin{gathered}
\tilde{X}=X / D \\
\tilde{Y}=Y / D
\end{gathered}
$$

where, $X$ and $Y$ were separately the streamwise and spanwise coordinate value of the electrode axis, $D$ was the groove width of the flame holder outer cover.

The electrode length $(E L)$ was defined as

$$
E L=H / 2-Z
$$

where, $H$ was the vertical height of outlet section for the test section, $Z$ was the vertical coordinate value of the electrode end inside the test section.

\section{Results and Discussions}

\subsection{Relationship between I and EL}

Effect of the $E L$ is shown in Figure 5. Figure (a), (b) and (c) respectively display the data from $\tilde{X}=0.75,1.50$ and 2.25 .

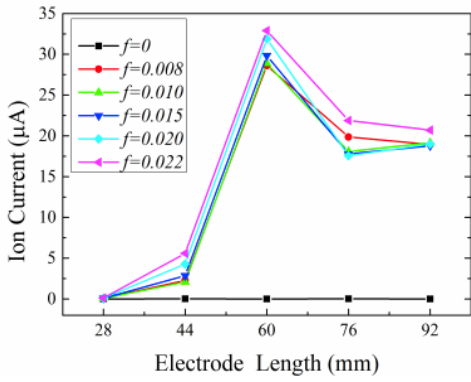

(a)

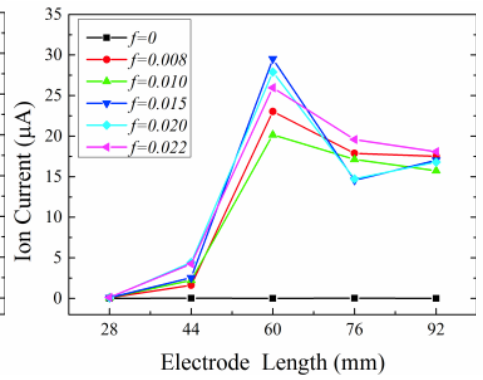

(b)

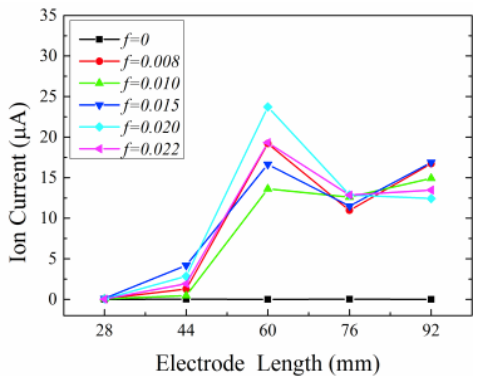

(c)

Figure 5. Ion current influenced by electrode length for $\tilde{X}=0.75(\mathrm{a}), 1.50(\mathrm{~b})$ and $2.25(\mathrm{c})$

In an attempt to exclude the possible effect of the vitiated air from the preburner, the $I$ was collected with different $E L$ when $f=0$. Results shown in Figure 5 suggest that when $f=0$, the $I$ remains zero throughout with the $E L$ increasing. Consequently, the preheated vitiated air had none effect on the $I$. One of the necessary conditions for ion current formation is the existence of charged ions. As mentioned above, chemiionization in flame front and thermal ionization under high temperatures are the main sources to provide ions. When only the preburner was operating, the flame couldn't propagate to the flame holder, and simultaneously vitiated air from the preburner couldn't be dissociated at the relatively low temperature of $623 \mathrm{~K}$. Therefore, the ion current obtained from the recirculation zone was zero, namely $I=0$.

According to the any diagram in Figure 5, when the $f$ ranges from 0.008 to 0.022 , the shapes of the relation curve between $I$ and $E L$ are approximately the same, which is mainly due to the similar fuel concentration distributions at different $f$ values.

As $E L$ increases, the $I$ increases first, and then suddenly decreases when $E L$ overs $60 \mathrm{~mm}$. Finally, it demonstrates a unimodal curve. The peak of ion current appears when $E L=60 \mathrm{~mm}$.

When $E L=28 \mathrm{~mm}$, the whole electrode was still not getting into the combustion zone and surrounded by the vitiated air from the preburner. There were not charged ions around the electrode, thus the $I$ remained zero, $I_{28}=0$. When $E L=44 \mathrm{~mm}$, the end of electrode had gone across the flame front and part of it was in recirculation zone. Ions produced in flame front and recirculation zone were captured by the electrode and the ion current formed, $I_{44}>0$. When $E L=60 \mathrm{~mm}$, the area of surface absorbing the charged particles increased further, which led to the continuous growth of the $I, I_{60}>I_{44}$. When $E L>76 \mathrm{~mm}$, adversely, the ion current decreased compared with that when $E L=60 \mathrm{~mm}$. Reasons for this phenomena can be attributed in two aspects. One is that when $E L=60 \mathrm{~mm}$, the electrode end 
was exactly in the middle section along the vertical direction, and thus exposed to the higher temperature burned gas more likely to dissociate into ions compared with the other situations. The other one is the end effect caused by the cylindrical electrode. Experimental results on a simple burner indicate the end effect from a cylindrical electrode resulted in the increased ion current by $75 \%[22]$.

\subsection{Relationship between I and $\tilde{X}$}

Effect of $\tilde{X}$ is shown in Figure 6. Figure (a), (b) and (c) respectively display the data from $E L=60 \mathrm{~mm}$, $76 \mathrm{~mm}$ and $92 \mathrm{~mm}$.

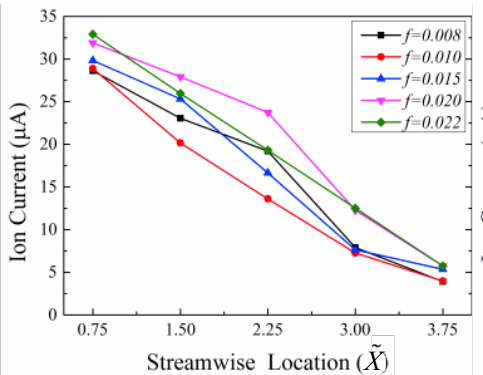

(a)

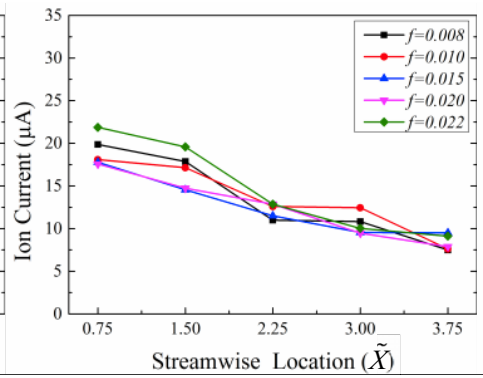

(b)

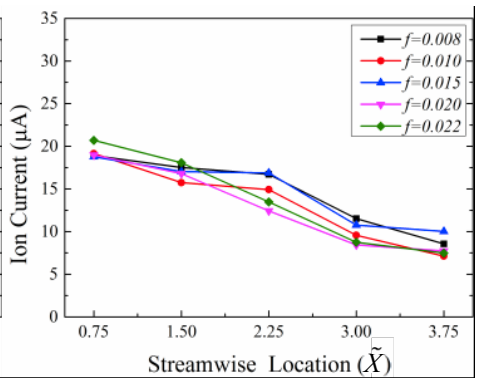

(c)

Figure 6. Ion current influenced by electrode streamwise location for $E L=60 \mathrm{~mm}(\mathrm{a}), 76 \mathrm{~mm}(\mathrm{~b})$ and $92 \mathrm{~mm}(\mathrm{c})$.

As illustrated in any diagram in Figure 6, the relationships between $I$ and $\tilde{X}$ under various $f$ ranging from 0.008 to 0.022 follow the same rule, which is also attributed to the similar fuel concentration distributions at different $f$ values.

With the $\tilde{X}$ increasing, the $I$ decreases linearly. When $E L=60 \mathrm{~mm}, I$ drops from $28 \sim 33 \mu A$ to $4 \sim 6 \mu A$. Then $E L$ grows to $76 \mathrm{~mm}, I$ declines from $17 \sim 22 \mu A$ to $8 \sim 10 \mu A$. After $E L$ reaches to $92 \mathrm{~mm}$, $I$ reduces from $19 \sim 21 \mu A$ to $7 \sim 10 \mu A$. The maximum reduction of the $I$ appears with $E L=60 \mathrm{~mm}$ by an average of $25.5 \mu A$.

The $I$ declines principally is attributed to the electric field intensity weakening. The flame divergence angle after a $\mathrm{V}$-type flameholder is generally $3 \sim 5^{\circ}$ and recirculation zone length of that is commonly 3 times of the groove width[23]. That implies the length of the electrode immerged into the high-temperature zones including combustion zone and recirculation zone is nearly the same, even $\tilde{X}$ changes in recirculation zone. Therefore, the increase of $\tilde{X}$ merely denotes the growth of distance between the positive and negative electrodes. The electric field intensity imposed by the bias voltage and the electrode gap are in inverse proportion. Moreover, $I$ is in direct proportion to the intensity. Hence, $I$ and $\tilde{X}$ are in inverse proportion, which means the $I$ declines linearly with the increase of $\tilde{X}$. The mathematical analysis and simulation of the ion current in an SI engine proves that the ion current is inversely proportional to the clearance of the electrodes[24].

\section{Conclusions}

The experimental study on the effect of electrode location on the ion current was conducted in the suction flame holder. The main conclusions are summarized as followed:

(1) When the fuel-air ratio ranges from 0.008 to 0.022 , the relationships between ion current and electrode length are approximately the same. With the electrode length increasing, the ion current demonstrates a unimodal curve. The peak of the ion current appears when electrode length equals $60 \mathrm{~mm}$.

(2) When the fuel-air ratio ranges from 0.008 to 0.022 , the relationships between ion current and electrode streamwise location are almost the same. With the streamwise location increasing, the ion current demonstrates a linear decreasing curve. The maximum reduction of the ion current appears when electrode length equals $60 \mathrm{~mm}$ by an average of $25.5 \mu \mathrm{A}$. 
(3) Because the larger ion current provides the wider range for setting the misfire threshold, the electrode length and location for this flame holder can be chosen as $E L=60 \mathrm{~mm}$ and $\tilde{X}=0.75$.

\section{Acknowledgement}

This research was financially supported by the National Natural Science Foundation of China (515060 03).

\section{References}

1. H. Lefebvre, D.R. Ballal, Gas Turbine Combustion: Alternative Fuel and Emission, Third Edition, 173 (CRC Press, Boca Raton, 2010)

2. Z.Q. Fu, Areoengine 3, 28-32 (1998)

3. Q.F. Cheng, J. Aerosp. Power. 3, 259-262 (1991)

4. J. Lovett, T. Brogan, D. Philippona, B. Kiel, T. Thompson, 40th AIAA/ASME/SAE/ASEE Joint Propulsion Conference and Exhibit, 4192

5. T. Muruganandam, S. Nair, Y. Neumeier, T. Lieuwen, J. Seitzman, 38th AIAA/ASME/SAE/ASEE Joint Propulsion Conference \& Exhibit, 3732 (2002)

6. S. Nair, T.M. Muruganandam, R. Olsen, A. Meyers, J. Seitzman, B. Zinn, T. Lieuwen, 42nd AIAA Aerospace Sciences Meeting and Exhibit, 138 (2004)

7. R. Bompelly, T. Lieuwen, J. Seitzman, 47th AIAA Aerospace Sciences Meeting Including The New Horizons Forum and Aerospace Exposition, 2009-0982 (2009)

8. R.K. Bompelly, J.M. Seitzman, ASME 2011 Turbo Expo:Turbine Technical Conference and Exposition, GT2011-46702 (2011)

9. T.X. Yi, E. Gutmark, 42nd AIAA/ASME/SAE/ASEE Joint Propulsion Conference \& Exhibit, 4738 (2006)

10. K. Aditya, T. Muruganandam, ASME 2012 Gas Turbine India Conference, GTINDIA2012-9585 (2012)

11. P. Strandh, M. Christensen, J. Bengtsson, R. Johansson, A. Vressner, P. Tunestal, B. Johansson, SAE Technical Paper, 2003-01-3216 (2003)

12. A. Vressner, A. Hultqvist, B. Johansson, SAE Technical Paper, 2005-01-2093 (2005)

13. A. Vressner, P. Strandh, A. Hultqvist, P. Tunestal, B. Johansson, SAE Technical Paper, 2004-010934 (2004)

14. D. Panousakis, A. Gazis, J. Patterson, R. Chen, J. Turner, N. Milovanovic, D. Blundel, SAE Technical Paper, 2006-01-0024 (2006)

15. G.Y. Dong, Y.L. Chen, Z.J. Wu, L.G. Li, R. Dibble, Proceedings of the 35th International Symposium on Combustion 3-35, 3097-3105 (2015)

16. B.T. Chorpening, J.D. Thornton, K.J. Benson, 4rth IEEE Conference on Sensors, 1597867 (2005)

17. S. Nair, R. Rajaram, A. Meyers, T. Lieuwen, L. Tozzi, K. Benson, 43rd AIAA Aerospace Sciences Meeting and Exhibit, 932 (2005)

18. S. Keshav, Y. Utkin, I.V. Adamovich, 46th AIAA Aerospace Sciences Meeting and Exhibit, 2008$1056(2008)$

19. A. Fialkov, PROG. ENERG. COMBUST. 5-6-23, 399-528 (1997)

20. A. Saitzkoff, R. Reinmann, F. Mauss, M. Glavmo, SAE Technical Paper, 970857 (1997)

21. S. Yoshiyama, E. Tomita, Y. Hamamoto, SAE Technical Paper, 2000-01-2828 (2000)

22. Y.M. Jin, Probe Technologies in Pyrometry, 196 (China Metrology Press, Beijing, 1988)

23. S.M. Bush, E.J. Gutmark, AIAA J. 3-45, 662-672 (2007)

24. J.W. Li, S.L. Liu, T.Y. Wang, W.Q. Liu, S.H. Yang, J. Tianjin Univ.(Sci. Techn.) S1-39, 66-70 (2006) 